\title{
Going beyond Triviality: The Toyota Production System-Lean Manufacturing beyond Muda and Kaizen
}

\author{
Bruno G. Rüttimann1, Martin T. Stöckli² \\ ${ }^{1}$ ETH Zürich IWF, Zurich, Switzerland \\ ${ }^{2}$ Inspire AG, Zurich, Switzerland \\ Email: bruno.ruettimann@inspire.ethz.ch, stoeckli@inspire.ethz.ch
}

Received 14 February 2016; accepted 3 April 2016; published 7 April 2016

Copyright (C) 2016 by authors and Scientific Research Publishing Inc.

This work is licensed under the Creative Commons Attribution International License (CC BY). http://creativecommons.org/licenses/by/4.0/

(c) (i) Open Access

\section{Abstract}

Personal consulting experience has been showing that even many proven managers responsible for Lean Six Sigma Operational Excellence (OPEX) techniques have not fully understood the profound and comprehensive significance of Lean. Apart from the idealized interpretation of Lean boiled down to the limited concepts of Muda and Kaizen, the classical "temple" representation of the Toyota Production System (TPS) often leads to the interpretation that Lean is a toolbox from which one can select supposedly independent tools. By picking just some tools, however, the full potential of the TPS certainly cannot be exploited and-in the worst case-it may even cause production disruption. This essay criticizes the wide-spread ultra-simplification of concepts and, as a consequence, the distorted interpretation leads to an inappropriate use of the Lean tools. It presents two additional representations of the classical TPS temple model stressing the intrinsic systemic effects as well as the underlying theory concepts of the TPS to allow a flawless Just-inTime (JIT) production. In fact, the original TPS is not a toolbox, but a comprehensive synergic tool system.

\section{Keywords}

Toyota Production System, Lean Manufacturing, Muda, Kaizen, Single Piece Flow, Mixed Product Cell, Multi Cell Production, Just in Time, Jidoka, Lean Tools, Mono-Pillar TPS Model

\section{Introduction}

A model is an abstraction of the reality. The system to be modeled might be a structure (static view), a process

How to cite this paper: Rüttimann, B.G. and Stöckli, M.T. (2016) Going beyond Triviality: The Toyota Production SystemLean Manufacturing beyond Muda and Kaizen. Journal of Service Science and Management, 9, 140-149. 
(dynamic view) or usually a combination of both. A model can be descriptive or graphical, suiting to represent a system and explaining concepts, or it can be mathematical, suiting to understand the behavior of a system. Whether the intrinsic design of the model is simple (black box) or complex (white box approach) depends on the detail to be modeled. Indeed, on the one hand, a model has not to be hyper-complex-otherwise we do not have a model, but we have again the real world; on the other hand it has not to be ultra-simple-otherwise the insights which can be obtained from the model are too limited and do not represent reality well enough. A good model is a model which serves for the purpose it is conceived.

Today, we are living in a world with an information overload, a situation that is confusing people (the Japanese call it Muri). This leads to the desire to simplify and sometimes even to ultra-simplify in order to be able to govern the complexity and to facilitate communication. Now, when consultants come into play, this situation often gets worse rather than better: Due to their high daily rates, the time slots given to consultants to explain, e.g. to the management team of a company, are usually short, forcing consultants to stick to the essential, especially if the topic is complex. The results are simple presentations typically with an appealing key message on each slide easy to be remembered. Such presentations are designed to be immediately understandable also for non-experts and talking in a language familiar to the audience. This consultant and management-oriented way of communication bears an intrinsic danger to over-simplify concepts with the result not to pass the real core message, but passing an idealized and distorted message of the situation. Further, the simplification has the sweet, but very dangerous side effect to remain superficial, not having to study the subject in detail with the consequence of not having captured the real complexity of the problem or system.

If today not really wrong, but distorted ideas circulate about Lean, therefore, also consultants and trainers bear a major responsibility. Indeed, talking about Muda is easier than to talk about Single Piece Flow (SPF), Mixed Product Cell (MPC), or Multi Cell Production (MCP), since waste is immediately associated with cost savings, for which one gets immediately the attention of western managers. Moreover, consultants often say what the management wants to hear as requested. The explanations in this paper might be simplified themselves, however, aimed at the core of the problem: the danger of ultra-simplification with the resulting distortion of means and ends.

This essay analyzes from where the distorted ideas of Lean originate and what they can cause. The paper does not pretend to be a comprehensive scientific essay about Lean, however, it gives a different and clear systematic view about the intrinsic nature what Lean also is.

\section{An Example to Understand the Problem}

Before entering into explaining the true nature of Lean, let us take a prototypical and real example. Recently we had the opportunity to visit a leading manufacturer in Switzerland. The very first impression was positive, typical of a company applying basic Lean techniques such as 5S, Kanban supermarkets, as well as Kaizen boards. The production manager explained to have attained 16 inventory turns. Attaining 16 turns does not necessarily require introducing Lean concepts, it can be achieved by a clever purchasing manager attentive to net working capital management. Of course the number of turns may vary from industry to industry and depends also from the standardization degree of the product, but Lean can allow achieving far more than 50 turns! Despite the 16 turns are not overwhelming, being Lean also a continuous improvement approach, the turns may thus rise further in future. Nevertheless, this company is more advanced regarding Lean implementation than many other Swiss companies and is happy about the reached progress so far. Looking closer to the production, it was perceivable though, that within the manufacturing cells no SPF has been applied, but the products were moved in batches showing a "fake flow", i.e. the superficial illusion of a SPF. The time was too short to verify the potential applicability of a real SPF and the production modality were driven by the available machining centers of course. But in the last implemented cell the evidence of misunderstanding basic concepts of Lean became evident. The production manager showed the latest generation of multiple axis work center with a well-equipped tools "pater noster" and commented that the new machine is able to perform a SPF which in fact had also been implemented. Discretely executed time measurements revealed that the total times for the tool changes more than equaled the total processing times of the pieces. This represents a lot of Muda, i.e. improvement potential. Batching the transfer units in this specific case, e.g. to six pieces, would have considerably improved productivity, avoiding multiplication of tool change time. This is a typical example showing two facts: on the one hand, the equipment manufacturer did not care about the suitability of his equipment to the real need of the customer 
and sold the machine to be SPF compatible and on the other hand, the customer did not know what type of equipment is best for a SPF (most likely neither the equipment manufacturer nor the customer really knew what Lean is introduced for). This example shows that SPF in presence of certain machining center does not give always the best result and the manufacturing "modus operandi" depends also from the available equipment. Moreover, it shows also that the main goal of Lean to implement SPF was not fully understood and even less how to implement it by considering Cycle Time (CT) in relation to customer's Takt Rate (TR). The conclusion is that having partial or distorted knowledge of Lean production techniques will result in non-optimal set-up of the manufacturing line. We will not go further into this matter and take it merely as an observed example, but the presented situation is not uncommon in Swiss industries (and most probably also elsewhere) and thoughtprovoking: while high-end universities and industries nowadays are thinking about the smart factory of the future and internet of things, many companies which are still applying obsolete production scheduling and production methods or are applying modern ones incorrectly, not having some unique selling propositions, will most probably not survive the end of this decade, and certainly will not reach the remote promised land of the smart factory.

Although the above shown situation is not optimal, the company has by far a better starting position to bring Lean to success than other manufacturing companies in Switzerland. Indeed, in many Swiss companies it is still believed that set-up time reducing SMED technique (Single Minute Exchange of Die) is carried out to gain more production capacity by reducing the non-value add set-up time, i.e. to chase explicitly Muda, whereas the original idea of SMED is to implement a mixed product cell, i.e. to lower the pitch to manufacture different products several times a day within the same cell to allow a JIT manufacturing. This is a typical example showing that the real aim of the TPS and its tools are often misunderstood.

\section{The Origins of Distorted Lean View}

As already mentioned, Lean is often identified with Muda and Kaizen. This extreme simplification considers the auditors to be ignorant and allows the presenters to be superficial, sometimes hiding their own lack of knowledge about Lean. Certain topics are in fact complex and the art is to explain the complexity, reducing it to the essential without becoming trivial and losing all the main aspects. For sure, identifying Lean with Muda and Kaizen is too simple and does not reflect the different concepts and techniques on which the TPS is based on to run a complex product manufacturing system and why the "toolbox" is needed as a whole.

The TPS has been built-up during several decades attaining the present state of perfection showing to everybody how to implement and run an efficient automotive manufacturing production system. The TPS has been described e.g. in [1] [2]. It has grown organically, attaining step by step perfection in self-learning cycles. The specific Japanese mentality may have favored the conception of this empowering manufacturing theory. It has also to be pinpointed that the whole system has been developed suiting best the assembly-type of manufacturing, as it is represented by the automotive assembly transfer lines. Nevertheless, it can be transposed to other types of manufacturing industries usually coming along with a reinterpretation of the model application within a changed context.

When the American professors Womack and Jones studied the TPS in the late 1980ies to investigate why the American automotive industry performed worse than the Japanese industry [3], they developed and provided later an approach to improve the present western manufacturing methods, which they called Lean [4]. Calling it the Toyota way in America would not have resulted optimal from a marketing point of view. Their approach to improve the American industry was not based on organic improvement as implemented by Toyota, but based on a revolutionary approach through a "present state-future state-action plan" change approach; this does not correspond to Kaizen (improvement by small steps), but to Kaikaku (improvement by big steps). Indeed, the American Lean interpretation of the TPS is designed for the western world to catch-up and is therefore twofold:

- Lean Transformation, regarding how to change fast and effectively, and the

- Lean Philosophy, regarding what to change and at what to aim at.

\subsection{The TPS Philosophy and Lean Thinking}

The original Lean philosophy compared to the TPS is simplified and usually "sold" as waste reduction (see also next chapter 4). This is not wrong per se, but the aim of TPS is much higher, with waste reduction being quasi a by-product. Indeed, Toyota developed exactly the necessary concepts to limit, or better to avoid, waste produc- 
tion having scarce availability of resources, especially after WW2. A synergic system of techniques have been put together around SPF (which, nota bene, is not a Toyota invention, but based on Taylorism and applied first in Ford's T-model production) to allow a flawless quality-oriented operation of a SPF without waste, as well as Heijunka-box leveled pitch to limit WIP (Work in Process, which is also considered as waste and delays PLT, Process Lead Time). Such as the TPS acronym suggests, the emphasis is put on the production system. It is a new way how to produce, how to maximize the output of assembly process type of operations by speeding up PLT, integrated by in-station guaranteed product quality. The TPS has not been conceived by applying manufacturing theory, but by attentive observation and evaluation how to best eliminate any waste and optimize process performance. Interesting is, that Toyota does not eliminate Muda per se, but via elimination of Mura, i.e. smoothening unevenness. Apart of the underlying tools (SMED, Heijunka-pitch) to create a smooth production scheduling, as well as the simple technique to control production triggering (Kanban), the TPS has also originated the continuous improvement approach (Kaizen). The striving for perfection by using the "hidden" knowledge of the operators at the base, where production takes place (Gemba), has been copied already very early by Western companies, creating the suggestion box system. This was a first timid attempt to implement the continuous improvement process, however far away from how it has been intended by the Japanese Kaizen approach. The final goal of the TPS has been the wasteless JIT production. At the end, it took three decades to develop what is called TPS today.

On the other hand, we have the American Lean approach. Already the naming is symptomatic what stands at the top of the goals: Lean reflects speed, waste elimination and cost reduction, i.e. performance translated into dollars. This is the straight forward oriented approach of Western enterprises to catch-up. The usually most taught Lean concepts are mainly all about VSM (Value Stream Mapping) and Muda identification and elimination as well as the Lean Transformation approach. In addition, a strong tool-based belief is at the core, which often deviates from the real origin of the problem itself. This is a different approach than the original TPS. This is not surprising; indeed, the TPS as an organically grown production system is i.e. a production philosophy, whereas Lean Thinking is the propagation of a "recipe".

It has also to be explicitly stated that the TPS has been developed to optimally match the assembly type production, but this does not mean, that it is not applicable to other types of manufacturing systems, as the Japanese shipyards already showed in the seventies. Nevertheless, in non-assembly industries, the Toyota production theory and techniques are reluctantly implemented, because resulting sometimes difficult to interpret the concepts and therefore how the tool has to be adapted to the different "process physics". The consequence is, to use only a part of the Lean tools limiting the exploitation of the real improvement potential. The limited use of the tools might also stem from the classic two pillar temple house representation of the TPS which we will consider again later (Figure 1) which might mislead to pick a few suitable tools just as needed.

Although, certain manufacturing processes are more suitable for the TPS than other processes, especially with regard to the service industry [5], the concepts have also been adopted by some other industries than the automotive or electronics with great success. Indeed, also the airplane industry headed by Boeing has moved from stationary assembly of airplanes to a paced flow assembly. Interesting to mention, as Jones from the LEI (Lean Enterprise Institute) states, already the Venetian Arsenal, the largest industrial site of the world in the 18th century, used concepts of standardized work and reduced transportation ways, implementing a sort of flow on the final assembling to build their cargo vessels. This clearly shows that certain manufacturing techniques are necessary to maximize production output and are intrinsic in the production system to optimize performance also with regard to PLT.

Lean thinking has conquered western production industry and the resulting benefit have also been noticed by the service industry, namely banking, administration, hospitals; however, exactly in the service industries Lean has according to our experience not been exploiting its full potential (in general of course, exceptions may confirm this statement) and waste is usually reduced by applying VSM and Gemba-walk. In the meantime, Lean has received a connotation like an omnipotent manufacturing philosophy; indeed, the maximum generalization of OPEX is now found in the neologism of Lean Management.

\subsection{Lean Transformation}

Now, to best transform an existing production system to the TPS standard, the Lean Transformation approach is applied. Indeed, the Lean Transformation [4], as it has been deployed by Womack's Lean Enterprise Institute (LEI), bases mainly on: 


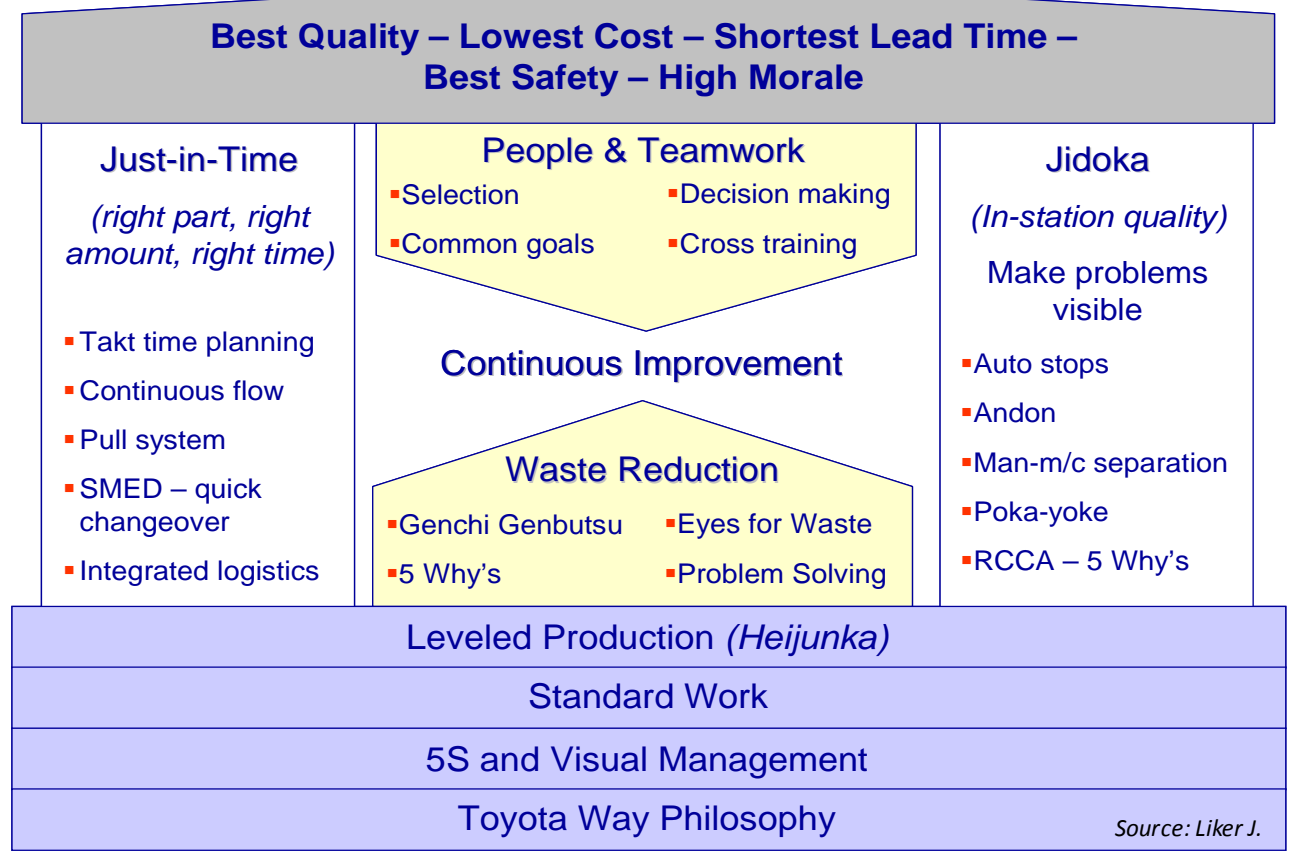

Figure 1. The classic representation of the TPS (two-pillar temple model).

-Identify the value stream,

-Show the value stream and eliminate waste,

-Transform the value stream by implementing flow on customer pull,

-Empower people,

-Strive for perfection.

This approach is clearly apt for a very efficient value stream transformation based on: "present state analysis, future state design, action plan implementation". In Europe, rather the classic Lean Introduction approach is applied with the roll-out beginning on the shopfloor starting with Hansei/Kaizen teams, 5S, followed usually by standardized work, TPM (Total Productive Maintenance) and so on, i.e. centered around shopfloor Kaizen culture, or other more or less successful partial deployment approaches [6].

The first two steps of the LEI transformation approach are executable in every industry or service company and transaction oriented activity. The Lean VSM is a very efficient approach. However, to transform a push into a pull manufacturing system in certain non-assembly industries may become tricky and in service industries it may even become impossible. Whereas $5 \mathrm{~S}$ can be applied everywhere, TPM is mainly restricted to manufacturing industries and reducing change-over time may even become a different meaning in transactional environment [5].

Therefore, Lean is often reduced to waste reduction (Muda) by Gemba walk and continuous improvement (Kaizen), i.e. the striving for perfection and this often not with the original recurring PDCA cycle, but with Lean Six Sigma DMAIC. However, LSS DMAIC does not bring any change of attitude into a production department let alone into a company. Indeed, DMAIC is a very effective and powerful problem solving approach, and here another mess has its origin, which will not be investigated in this essay (see also [6]).

The concept to eliminate waste (i.e. transportation, inventory, waiting, overproduction, scrap and so on) is not wrong and in addition easy understandable by everybody, but it does not consider the overall situation, i.e. how to improve an underperforming manufacturing system. Whereas in the automotive industry high performance SPF transfer lines are the standard, which are the ultimate aims to gain fast and high throughput, traditional industries are still struggling with underperforming "batch \& queue" production (this at least is presently still the case in many Swiss companies which, due to the absence of an automotive industry, lack this culture). It is therefore not surprising that consultants focus on the waste reduction exercise based on Gemba walks-but that is not Lean in the original TPS comprehensive sense; the Gemba walk is only an ancillary technique to reduce Muda. 
Further, the proliferation of dedicated approaches such as Lean administration, Lean medical, Lean banking, Lean office, and so on, does not help to overcome the problem of the root cause, but enforces a tool approach, Lean becoming a catchword loosing the original synergic power of the original TPS and limited to mere VSM and the hunt to discover waste. To apply Lean effectively in the office (the industrialization of the bank, how Sergio Ermotti, CEO of UBS, called it) one has to understand Lean in the manufacturing environment to begin with. Having done that, the application of TPS needs to be accordingly however, differentiated and with an adapted interpretation of the whole TPS [5]. At this point the core question emerges: What is the essence of Lean?

\section{Alternative Representations of the TPS}

A system intrinsically has interacting variables; therefore, a static representation of the system without covering the interaction aspect does not give the appropriate view of the working mechanism and may lead to a superficial interpretation and use of the model. The systemic behavior of a system has to be shown and should therefore present "some arrows" indicating visually the inductive logic and functional interaction, i.e. the linking of supportive concepts leading to the JIT target. We can see this by analyzing an organization, representing a complex system. Indeed, an organization is always represented by an organizational chart (static view) and process chart (dynamic view), the dynamic view being much more important because an enterprise's daily business is functioning primarily through processes and not through hierarchical positions.

For this reason-although Liker itself talks about a tools system—-the classic TPS temple model(s) may have led to simplified interpretations such as to eliminate explicitly Muda, if studied superficially, although it clearly shows the foundation of Lean, the two main pillars of Lean (JIT and Jidoka), and the embracing roof of the Toyota goals and working philosophy of continuous improvement (Figure 1).

\subsection{The Sequential Mono-Pillar Representation of TPS}

To highlight the synergic interaction of the systemic TPS elements, it is advisable to teach students the Lean approach with an integrated presentation of the JIT and Jidoka concepts within a mono-pillar model as shown in Figure 2 [7]. Indeed, being the final aim to have "the right product with the right quality" the Jidoka based inline or in-station quality should not be shown separate from the JIT flow pillar, as displayed by the classic twopillar TPS temple model of Figure 1, built-in quality becoming one element among others to implement a flawless SPF (Figure 2).

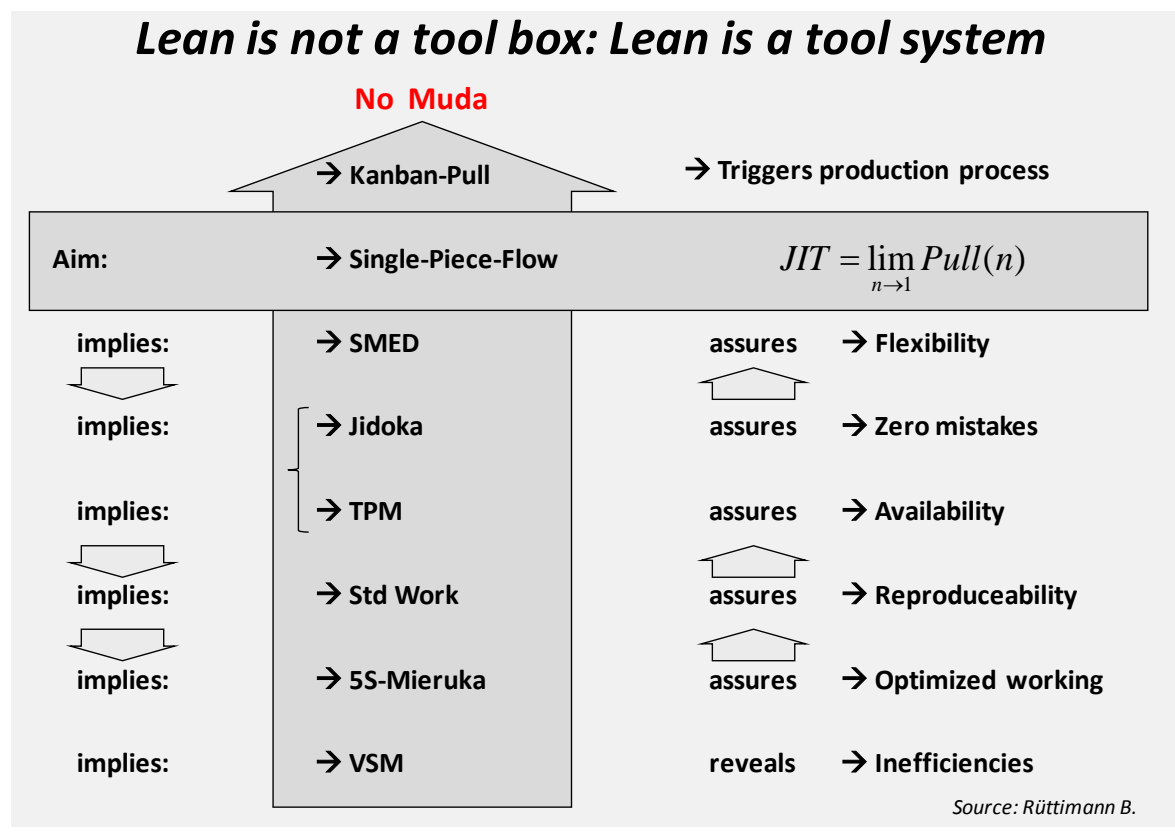

Figure 2. Simplified sequential mono-pillar model of the TPS. 
If ever a "multi-pillar" representation is used, the parallel concept to Jidoka (manufacturing quality parts) should also be TPM (Total Productive Maintenance) assuring the correct functioning of the equipment, with TPM being as much important as quality to allow a flawless SPF. Such as the various techniques of Jidoka (Poka Yoke, Andon, stopping line culture,...) also TPM techniques (maintenance prevention, preventive maintenance, predictive maintenance, autonomous maintenance) have to be put into place to guarantee the full operability of the line.

This mono-pillar representation shows the cascaded requirements to implement a flawless SPF. This model is a first attempt to show the system's interactions in a simplified way between the main Lean tools. It points at the intrinsic aim to have a SPF in order to gain speed for reducing process lead time and to increase productivity. It shows also that Kanban stocks are not the aim, despite it is sometimes understood so. The model of Figure 2 reveals a quite different aspect of the TPS than the two-pillar temple model of Figure 1; namely the real intrinsic nature of the theory of Lean regarding the Lean tools (neglecting for simplicity the Kaizen aspect of Lean, i.e. continuous improvement).

It shows clearly that Lean is not a toolbox, but a tool system. It explains that standardized work is needed to assure reproduceability of different operators, being part of a takted line. It shows also that TPM is required to assure availability of the equipment to implement a SPF. Indeed, in western companies TPM is still implemented with the intention to have less downtime and to supposedly increase output. But in the TPS, the TPM is necessary, because the absence of a good TPM would stop the whole line within a SPF production, reducing immediately the output of the whole line, whereas in the "batch \& queue" mode the downstream equipment can continue to produce due to the WIP in front of the operation, with WIP being a sort of operational buffer. It has to be stressed that it is an illusion to think that TPM increases the output; indeed, the output is given by the bottleneck [8]. All the attention should be drawn to the bottleneck of the operation, reflected by the "shadow price" of Linear Programming optimization models [9], impacting directly profitability. Furthermore, the model shows that Jidoka and Poka Yoke are necessary to implement in-line quality control and to avoid transferring a defective product to the next production station to assure, among others, the production of the right scheduled quantity. SMED is a technique to reduce change-over times. In western companies change-over time usually is reduced to have supposedly higher production capacity available, whereas in the TPS change-over time is reduced to allow mixed product cell manufacturing for a Heijunka box leveled pitch scheduling with reduced batch size.

All this is focused to implement a safe disruption-free SPF triggered by customer pull. It clearly shows that Lean is not a toolbox from which to select just a nice tool, Lean is a tool system of which every tool has to be put in place to assure a flawless production. Implementing this tool system eliminates automatically and implicitly most of Muda. However, even this model is not apt to show the interoperability of tools for a complex product manufacturing system which certainly will need to go more into detail.

\subsection{An Alternative Model of the TPS to Explain the Interaction of Manufacturing Concepts}

The required main techniques to implement a flawless SPF of a transfer line or a manufacturing cell have been shown in Figure 2. A real manufacturing environment, however, is made of several products needing several machining operations performed in different cells. These cells $C_{j}$ or better shopfloor ateliers comprise usual processing-technologies such as sawing, machining, grinding, welding, heat treatment (often batch operated), surface treatment, assembly and painting. The simplest production case is the mono product manufacturing, ideal for the introduction of a SPF to reduce PLT. This is done by minimizing WIP with a takted production line. To guarantee the correct pace of the line, the already seen techniques such as 5S, standard work, TPM, Jidoka, cell design have to be put in place. When multiple products are manufactured within the same cell (mixed product cell manufacturing), still maintaining a SPF, a further complication has to be mastered. Indeed, the batches $B_{k}$ have to be sized to the Takt Rate $\mathrm{TR}_{k}$ and the Workstation Turnover Time $\mathrm{WTT}_{\mathrm{j}}$ of the cell $\mathrm{C}_{\mathrm{j}}$ if a JIT delivery of several products is required. The applied techniques for this purpose are SMED and Heijunka box scheduling. The production situation is often a complex product manufacturing environment comprising different processing-technologies in different cells. In this further extended complexity, several manufacturing cells are linked together via strategic buffers, called supermarkets. Such buffers decouple the non-synchronized demand (D) of the downstream cell to the supply (S) of the upstream cell due to different cycle times (CT) of operations within the cells [9]. The replenishment of the supermarkets is self-regulated via Kanban, triggering the produc- 
tion when a stockout approaches. And finally, the requirements to be observed for a customer on-time-delivery (OTD), is that the smallest Exit Rate $\mathrm{ER}_{\mathrm{j}}$ of all cells $\mathrm{C}_{\mathrm{j}}$ has to be greater than the required TR, and that the Process Lead Time $\mathrm{PLT}_{\mathrm{Z}}$ of the last, i.e. of the customer "visible" processing step Z-corresponding to the manufacturing order entry point-have to be shorter than the Expected Delivery Time (EDT) of the customer. These are the necessary and sufficient conditions for an OTD. This means finally fulfilling a customer JIT supply. Such an extended model is shown in Figure 3 [10] which reflects the mathematical full induction or backward-chaining concept (i.e. from the individual to the general view), going from the mono product manufacturing, via the multi product manufacturing to the complex product manufacturing. It represents the increased complexity related to in-bound logistics.

All these interactions are shown in the cognitive model of Figure 3, a comprehensive, but simplified view of the modular construction of the TPS-Lean Model, showing also the rationale for each logical manufacturing complexity. It clearly states the goal of the concepts and which technique needs to be applied in order to satisfy the requirements to achieve the overall goal. In addition, the shopfloor continuous improvement is shown too (Kaizen teams), which represents the daily small improvements on all stages. Indeed, the final vision of "the right product with the right quality and the right quantity at the right place on the right time without Muda" needs the implementation of all TPS techniques which transform the underlying theory into action, will implicitly lead to eliminate Muda. Western companies probably have the impulse to add "at the lowest cost" to this final vision, what, however, is not necessary, since achieving this vision implicitly leads to lowest cost.

Figure 3 exemplarily shows in a simplified manner the multiple tasks of producing within a lean-optimized complex manufacturing environment. It shows synergic concepts and techniques and how they work together (also simplified, but explicitly modeled). In Figure 3 the word tool has by purpose been replaced by technique to emphasize the aspect of necessary requirement to be used; indeed, a tool may be used or not, a technique has more relevance with regards to the "how" the theory is applied. Implementing all these concepts with the available techniques will automatically reduce the major part of waste in form of transport, inventories and WIP, waiting time which is mainly queuing time, overproduction, and quality issues. The TPS is therefore an implicit way to reduce much of Muda simply by implementing the TPS techniques and elevating manufacturing performance to the highest score. On the contrary, the Lean approach, as the reduced western approach of VSM (VSM which is not a TPS tool, but was invented by the Americans [11]) is an explicit way to show and to eliminate Muda in some way, this is especially the case in service companies. It is now evident, that the often applied Lean approach is not completely identically with the TPS, despite Lean and TPS are considered to be synonyms.

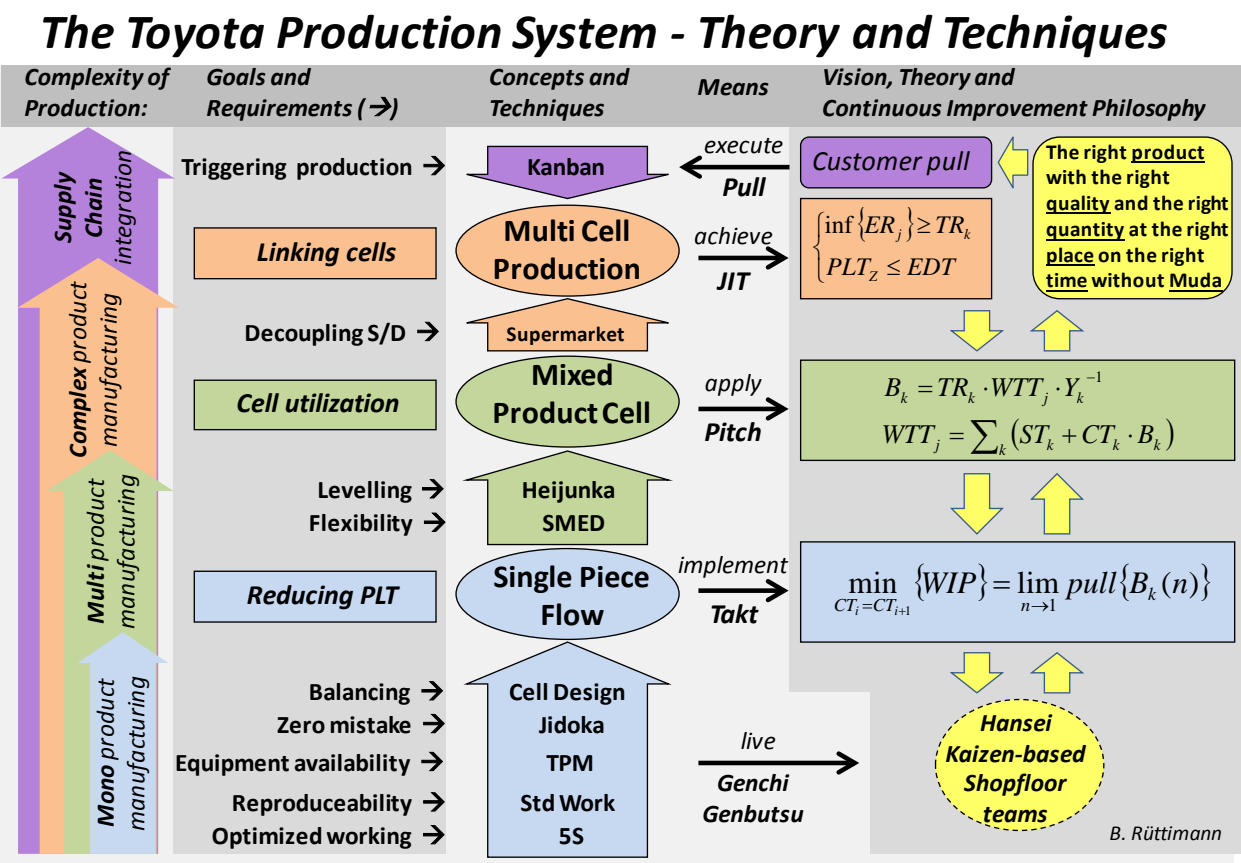

Figure 3. Comprehensive multi-level mono-pillar model representation of the TPS. 
Indeed, TPS is an organically grown system having nearly attained perfection with Toyota whereas Lean thinking-being an emulation of the TPS - comprises the explicit transformation from "batch \& queue" to SPF as well as the explicit focus on waste reduction in order to improve the manufacturing system. Although, performing a VSM exercise, showing Muda and recursive loops "to lean it up", is only a limited view of Lean, but often applied, nevertheless, it is for sure the ideal approach for starting the Lean journey to achieve OPEX. Indeed, VSM is one of the most powerful tools of Lean to understand basic manufacturing principles, how the manufacturing system works and to begin the Lean transformation of western companies not only in industries, but also in services.

The evidence is appearing that from "Lean Thinking" chasing Muda and by the effective communication to reduce Muda, is a target-hitting powerful marketing slogan, finally to "lean-up" everything. On the contrary, the TPS bears a solid and perfect production theory which contrasts the western "batch \& queue" approach going beyond explicit Muda reduction. Therefore, to explain Lean with trivial "Muda reduction" is indeed far too limited and should be avoided and the comprehensive sense of Lean including the systemic theory aspects should be divulged too. The auditors, being capable to understand the principles of a complex production system, have the right to be taken seriously avoiding trivial errors during OPEX deployment.

In order not to banalize the proven TPS with saying that Lean equals Muda eradication, it is preferable to describe Lean as a "Kaizen-based JIT production". This definition covers the implicit Muda reduction by saying how it is realized (JIT production) as well as the strive for perfection (Kaizen). Also here, "Kaizen-based" is not meant as the American blitz Kaizen technique, but the Japanese continuous improvement technique in-line with the TPS philosophy and Deming's PDCA cycle. For those who prefer the beauty of mathematic representation, Lean can be expressed simply with

$$
J I T=\lim _{n \rightarrow 1} \operatorname{Pull}(n)
$$

which of course is another simplification that, however, does not stress the Muda reduction aspect, but how it is implemented. A subtle difference how to approach and consider the maturity of the audience!

\section{Conclusions}

It is important to always keep the main goals in mind. This is especially true when implementing TPS. The mentioned examples show that the intrinsic governing concepts can get lost. The classic two-pillar TPS representation tends to seduce to just pick some tools out of the TPS and might have supported a narrow-minded view. In every case, tool-picking allows attaining a certain improved but non-optimal, and probably unstable level. Therefore it is important to present new representations of TPS that show the interactions between the tools and how they mutually require each other such as the two presented mono-pillar models.

The innovative content of this paper lies exactly in the two additional alternative representations of the TPS model stressing the synergic as well as theoretic aspects of the elements of the TPS. This critical examination and comparison of the models reveal the implicit systemic effects of working mechanism on Muda. They show clearly that Muda cannot be eliminated completely by the western VSM Muda approach, but is automatically eliminated as a whole, intrinsically, with the implementation of the comprehensive TPS/Lean tool system. With the presented new models, the goal is defined as the overall optimum of a self-regulated improving production system.

On the other hand, the effect of the human dimension of the TPS is left aside in the first alternative model and only mentioned by the way in the second one-not because it might be considered unimportant. To the contrary, we are well conscious about the overwhelming importance of employees' contribution to the success of introducing Lean in a company and to the operation according to the Kaizen approach. Simply, the focus was put on the theoretic elements. Indeed, the complex theoretic framework is assisted by the human capability with the continuous improvement philosophy of shopfloor Kaizen teams, which embodies the daily strive of a learning organization to pursue with unrelenting passion the ultimate target of operational excellence.

\section{References}

[1] Ohno, T. (1988) Toyota Production System: Beyond Large Scale Production. Productivity Press, New York.

[2] Liker, J.K. (2004) The Toyota Way, 14 Management Principles from the World's Greatest Manufacturer. McGrawHill, New York. 
[3] Womack, J.P., Jones, D.T. and Roos, D. (1990) The Machine that Changed the World. Free Press, New York.

[4] Womack, J.P. and Jones, D.T. (2003) Lean Thinking. Free Press, New York.

[5] Rüttimann, B.G., Fischer, U.P. and Stöckli, M.T. (2014) Leveraging Lean in the Office: Lean Office Needs a Novel and Differentiated Approach. Journal of Service Science and Management, 7, 352-360.

[6] Rüttimann B.G. and Stöckli M.T. (2015) Reasons for Operational Excellence Deployment Failures and How to Avoid Them. Journal of Service Science and Management, 8, 612-618. http://dx.doi.org/10.4236/jssm.2015.84061

[7] Rüttimann, B. and Wegener, K. (2014) Einführung in die Methoden von Lean Manufacturing und Six Sigma Quality Management. ETH Tools-IV Kurs, Lecturing Notes HS2014, D-MAVT.

[8] Goldratt, E. and Cox, J. (1984) The Goal: Excellence in Manufacturing. North River Press, Great Barrington.

[9] Rüttimann, B.G. (2015) Discourse about Linear Programming and Lean Manufacturing: Two Different Approaches with a Similar, Converging Rational. Journal of Service Science and Management, 8, 85-91.

[10] Rüttimann, B. (2015) Von Lean zu Industrie 4.0-eine Evolution? Von einer visionären Idee zum realen Verständnis. Presentation Held at Fertigungstechnisches Kolloquium, 26 November 2015, ETH Zurich/IWF, Switzerland.

[11] Rother, M. and Shook, J. (2003) Learning to See. Lean Enterprise Institute (LEI), Cambridge Center, Cambridge. 